Review began 01/03/2022 Review ended 01/12/2022 Published 01/13/2022

๑) Copyright 2022

Iftikhar et al. This is an open access article distributed under the terms of the Creative Commons Attribution License CC-BY 4.0., which permits unrestricted use, distribution, and reproduction in any medium, provided the original author and source are credited.

\section{Acute Calculous Cholecystitis With Sinus Bradycardia: Cope's Sign Encountered}

\author{
Haris Iftikhar ${ }^{1}$, Feroze Salahuddin Khan ${ }^{2}$, Nood Dhafi R. Al-Marri ${ }^{1}$, Hany A. Zaki ${ }^{1}$, Maarij Masood ${ }^{1}$ \\ 1. Emergency Medicine, Hamad Medical Corporation, Doha, QAT 2. General Practice, Health Education England, \\ Coventry, GBR
}

Corresponding author: Haris Iftikhar, haris.ifti@gmail.com

\begin{abstract}
Acute cholecystitis and cardiac ischemia can have a similar clinical presentation in some patients. Nonspecific electrocardiographic changes and arrhythmias can occur in acute cholecystitis and gallbladder disease that can confuse the treating physician leading to extensive cardiac workup. Emergency physicians and cardiologists should be aware of these changes so they can expedite the management of acute cholecystitis, which can lead to the resolution of these changes. We report a case of a 53-year-old male who presented with diffuse abdominal pain, nausea, and vomiting. His ECG showed sinus bradycardia. Imaging confirmed the diagnosis of acute calculous cholecystitis. His cardiac workup was unremarkable. His sinus bradycardia was resolved with the management of acute cholecystitis. This case highlights the possibility of a "cardio-biliary reflex" that is initiated by gallbladder pain via autonomic vagal innervation.
\end{abstract}

Categories: Emergency Medicine

Keywords: cardio-biliary reflex, bradycardia, gall bladder, biliary colic, cholelithiasis, cholecystitis

\section{Introduction}

Acute cholecystitis and cardiac ischemia can have a similar clinical presentation in some patients. Nonspecific electrocardiographic changes and arrhythmias can occur in acute cholecystitis and gallbladder disease that can further confuse the treating physician, leading to extensive cardiac workup. A vagally mediated cardio-biliary reflex is the proposed cause of some of these changes [1-3]. O'Reilly and Krauthamer were the first to highlight the association between calculous cholecystitis and sinus bradycardia. "Cope's sign" was named after Sir Zachary Cope. He was the first patient and surgeon to report the association of heavy epigastric/central chest pain, attacks of perspiration, and tachycardia with biliary disease [3]. Since the initial publication of two cases, only a few such cases of Cope's sign have been reported in medical literature, each showcasing some variation of altered heart rhythm in a patient with biliary disease. Due to the paucity of literature on this phenomenon, it is important to report this case where a patient presenting with acute calculous cholecystitis was found to have significant sinus bradycardia at presentation.

\section{Case Presentation}

A 53-year-old male presented to emergency medical services at the emergency department (ED), complaining of generalized abdominal pain. The pain was colicky and described as mild but continuous. The onset of pain was one day ago. He had nausea with vomiting three times before presentation. He denied any fever, weight loss, anorexia, or change in bowel or urinary habits. There was no significant past medical or surgical history and family history of cardiac disease. He was not using any medications. He denied smoking and alcohol consumption. He had no known allergies. Physical examination showed a temperature of $37^{\circ} \mathrm{C}$, blood pressure of $102 / 64 \mathrm{mmHg}$, respiratory rate of 18 breaths/min, pulse rate of 33 beats/min, and saturation of $99 \%$ on room air. His respiratory and cardiovascular exam was unremarkable. His abdominal examination showed epigastric tenderness with a negative Murphy's sign. There was no guarding or rigidity. The rest of his physical exam was also unremarkable.

An electrocardiogram (ECG) was recorded, which showed sinus bradycardia of 38 beats/min with mild QT interval prolongation (Figure 1). There was no heart block or ST changes. Initial workup was started to evaluate his abdominal pain and to exclude any cardiac pathology. His bedside random blood sugar was 5 $\mathrm{mmol} / \mathrm{l}$. Laboratory and radiological investigations (Figure 2) confirmed the diagnosis of acute calculous cholecystitis with high-sensitivity cardiac troponin T assay and thyroid function tests within the normal range. A follow-up ECG again showed sinus bradycardia of 36 beats per minute. Cardiology was consulted to evaluate for his sinus bradycardia and borderline QTc interval prolongation. Cardiology evaluation by Holter monitoring and echocardiography was normal. The patient was admitted under the care of the surgery team and offered emergency laparoscopic cholecystectomy, which he refused. He was managed conservatively and his heart rate was normalized after two days of medical treatment. 


\section{Cureus}

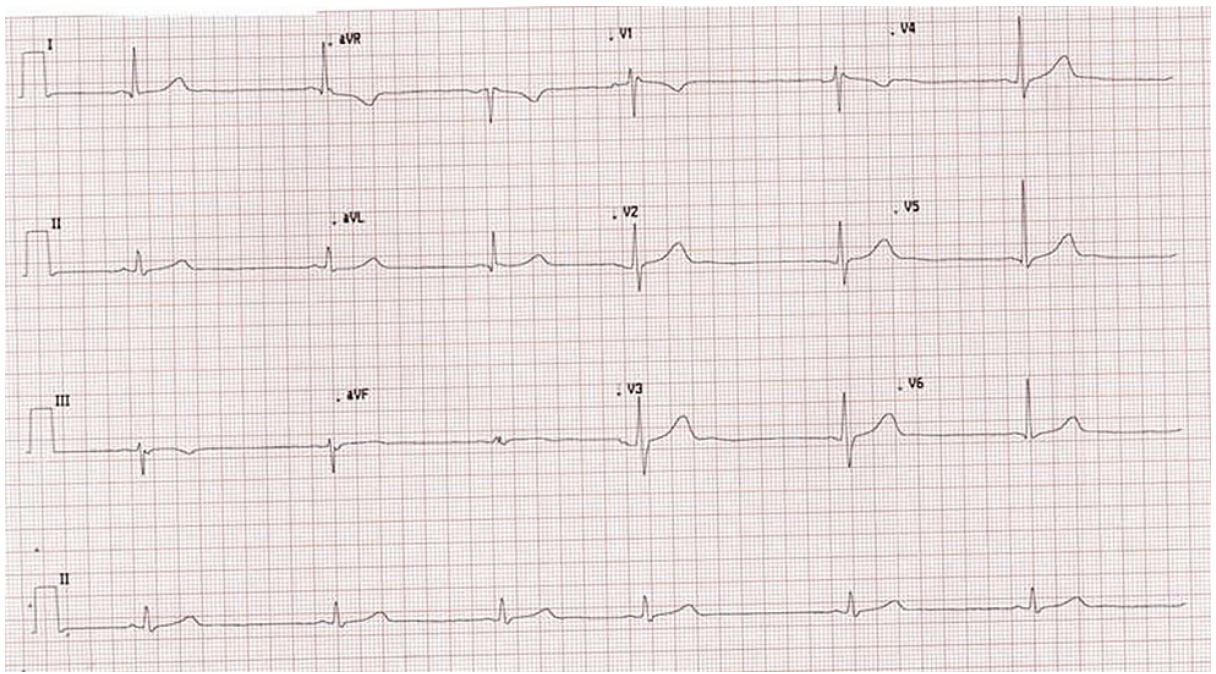

FIGURE 1: Electrocardiogram (ECG) showing sinus bradycardia and borderline QTc prolongation (QT/QTc: 549/467)

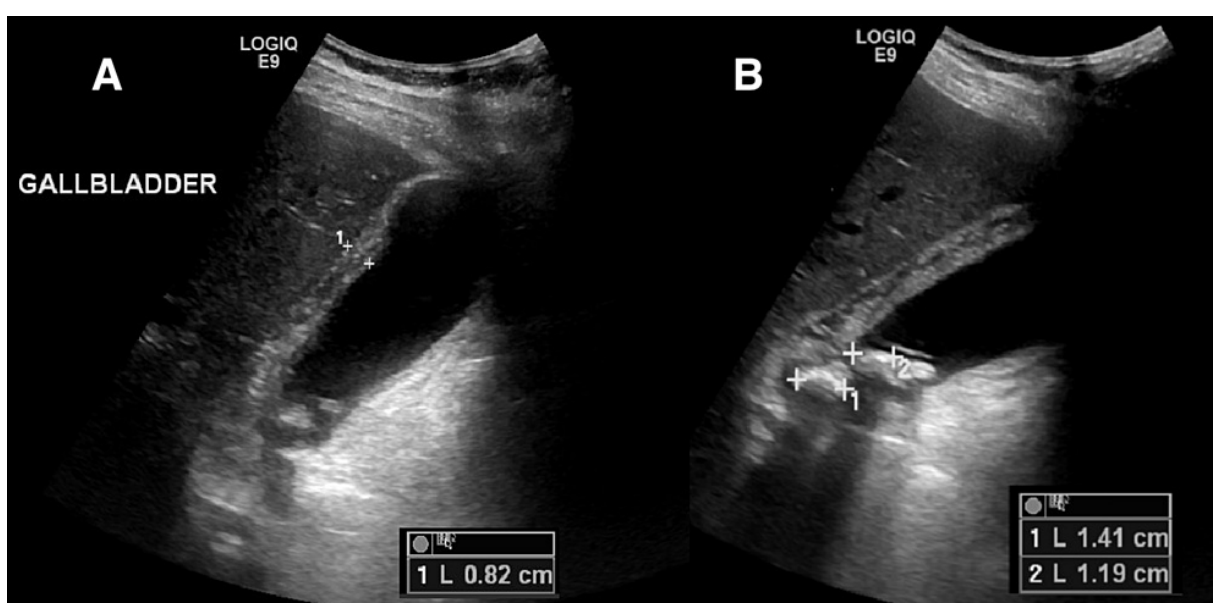

FIGURE 2: Ultrasound gallbladder showing acute calculous cholecystitis

A: The gallbladder (GB) wall is thickened and edematous and measures $8.2 \mathrm{~mm}$. Gallbladder is distended.

B: Multiple stones are noted interspersed with sludge. The largest stone measures $14 \mathrm{~mm}$. The rim of pericholecystic fluid is noted around the gallbladder.

\section{Discussion}

Reflex sinus bradycardia due to acute cholecystitis or Cope's sign was first described by O'Reilly and Krauthamer in 1971 [3]. Most cases described in the literature had sinus bradycardia with periods of either complete AV block or sinoatrial exit block as summarized in Table 1. Our case is unique, as this is the third case after the first two cases (Table 1) where there was only sinus bradycardia with acute cholecystitis without any kind of AV or SA exit block. In our literature search, we have identified a total of 10 cases of bradycardia associated with gallbladder disease. Seven were due to acute calculous cholecystitis and one each due to acalculous cholecystitis, biliary colic, and gall bladder torsion. All these cases had resolution of bradycardia with the treatment of gallbladder disease, except one by Scott et al. where ECG findings and resolution were not mentioned [1-11]. 


\section{Cureus}

\begin{tabular}{|c|c|c|c|c|}
\hline Year & Authors & ECG Findings & Diagnosis & $\begin{array}{l}\text { Resolution of ECG } \\
\text { findings }\end{array}$ \\
\hline 1971 & $\begin{array}{l}\text { O'Reilly \& } \\
\text { Krauthamer [3] }\end{array}$ & Sinus bradycardia (2 patients) & $\begin{array}{l}\text { Acute on chronic necrotizing } \\
\text { calculous cholecystitis }\end{array}$ & Yes \\
\hline 1999 & Vloka et al. [4] & $\begin{array}{l}\text { Severe sinus bradycardia leading to high degree } \\
\text { AV block and asystole }\end{array}$ & $\begin{array}{l}\text { Gangrenous acute on chronic } \\
\text { calculous cholecystitis }\end{array}$ & Yes \\
\hline 2009 & Franzen et al. [5] & $\begin{array}{l}\text { Complete AV block without escape rhythm for } 9 \\
\text { seconds }\end{array}$ & Acute calculous cholecystitis & Yes \\
\hline 2011 & Akyel et al. [6] & $\begin{array}{l}\text { Idioventricular rhythm with sinus capture beats, } \\
\text { sinus bradycardia }\end{array}$ & Acute calculous cholecystitis & Yes \\
\hline 2015 & Lau et al. [7] & Sinus bradycardia with sinus pauses & Acalculous cholecystitis & Yes \\
\hline 2015 & Sorić et al. [8] & $\begin{array}{l}\text { Complete AV block with a ventricular escape } \\
\text { rhythm }\end{array}$ & $\begin{array}{l}\text { Gangrenous acute calculous } \\
\text { cholecystitis }\end{array}$ & Yes \\
\hline 2018 & $\begin{array}{l}\text { Papakonstantinou } \\
\text { et al. [9] }\end{array}$ & $\begin{array}{l}\text { Sinus bradycardia with a brief period of complete } \\
\text { AV block }\end{array}$ & Biliary colic & Yes \\
\hline 2020 & Kumar et al. [10] & $\begin{array}{l}\text { Sinus bradycardia leading to periods of complete } \\
\text { AV block }\end{array}$ & Acute calculous cholecystitis & Yes \\
\hline 2021 & Scott et al. [11] & Bradycardia (ECG not mentioned in the article) & Gall bladder torsion & Not described \\
\hline
\end{tabular}

TABLE 1: Summary of the findings from the literature review

It is postulated that a "cardio-biliary reflex" exists that is triggered by gallbladder pain via autonomic vagal innervation. It can occur in cases of gall bladder disease with or without gall stones [7].

\section{Conclusions}

If we consider the patient's presentation, normal cardiac workup, and resolution of the sinus bradycardia with conservative management of the acute cholecystitis, this patient likely had a case of cardio-biliary reflex. All such cases require special consideration. The altered cardiac rhythm can not only complicate a case of acute cholecystitis but may be part of the initial presentation, thus acting as a confounder to the diagnosis. Further studies may help better delineate this interesting association.

\section{Additional Information}

\section{Disclosures}

Human subjects: Consent was obtained or waived by all participants in this study. Conflicts of interest: In compliance with the ICMJE uniform disclosure form, all authors declare the following: Payment/services info: All authors have declared that no financial support was received from any organization for the submitted work. Financial relationships: All authors have declared that they have no financial relationships at present or within the previous three years with any organizations that might have an interest in the submitted work. Other relationships: All authors have declared that there are no other relationships or activities that could appear to have influenced the submitted work.

\section{References}

1. Dickerman JL: Electrocardiographic changes in acute cholecystitis . J Am Osteopath Assoc. 1989, 89:630-5. 10.1515/jom-1989-890510

2. Krasna MJ, Flancbaum L: Electrocardiographic changes in cardiac patients with acute gallbladder disease . Am Surg. 1986, 52:541-3.

3. O'Reilly MV, Krauthamer MJ: "Cope's sign" and reflex bradycardia in two patients with cholecystitis . Br Med J. 1971, 2:146. 10.1136/bmj.2.5754.146

4. Vloka ME, Tamis JE, Steinberg JS: Neurally mediated syncope in 2 patients with extracardiac disease . Arch Intern Med. 1999, 159:625-7. 10.1001/archinte.159.6.625

5. Franzen D, Jung S, Fatio R, Brunckhorst CB: Complete atrioventricular block in a patient with acute cholecystitis: a case of cardio-biliary reflex?. Eur J Emerg Med. 2009, 16:346-7. 10.1097/MEJ.0b013e32832baed8

6. Akyel A, Yayla C, Kunak T, Yaman B, Tavil Y, Boyaci B: Idioventricular rhythm in a patient with acute cholecystitis. Clin Res Hepatol Gastroenterol. 2011, 35:774-6. 10.1016/j.clinre.2011.07.014

7. Lau YM, Hui WM, Lau CP: Asystole complicating acalculous cholecystitis, the "Cope's sign" revisited . Int J 


\section{Cureus}

Cardiol. 2015, 182:447-8. 10.1016/j.ijcard.2014.12.153

8. Sorić M, Miletić W, Žiga S, Grabovac V: Intermittent complete heart block in acute calculous cholecystitis . Signa Vitae. 2015, 10:53-4. 10.22514/sv101.062015.14

9. Papakonstantinou PE, Asimakopoulou NI, Kanoupakis E, Maragkoudakis S, Panagiotakis S, Gikas A: Cope's sign and complete heart block in a 78-year-old patient with biliary colic. Int Emerg Nurs. 2018, 37:3-5. 10.1016/j.ienj.2017.10.002

10. Kumar N, Kumar P, Dubey P, Kumar A, Kumar A: Cope's sign and complete heart block secondary to acute cholecystitis: a case report. J Acute Dis. 2020, 9:176. 10.4103/2221-6189.288597

11. Scott B, Hameed A, Knox R: Bradycardia and syncope: the case of the torted gallbladder . ANZ J Surg. 2021, 91:E50-1. 10.1111/ans.16110 